\title{
Orofacial Pain Anti-Inflammatory Activity of Extracts of Boswellia Serrata in Rats
}

\author{
Ja-Hyeong Choi ${ }^{*}$ Kyung-Yae Hyun ${ }^{* *}$ and Min-Kyung Lee ${ }^{\dagger, * *}$ \\ Department of Biomedical Health Science, Dong-eui University, Busan 47340, Korea
}

\begin{abstract}
Recently, many researches regarding the natural products which alternate with chemical products have been done. Among them, boswellia is well known for effect on anti-oxidative effect and inflammation. The aim was the effect boswellia of formalin- induced orofacial and temporomandibular joint (TMJ) pain on experimental animals was investigated. Experiments were carried out using subcutaneous (SC) pain model and TMJ pain model that were induced by the injection of $5 \%$ formalin into the right vibrissa pad $(\mathrm{SC}, 50 \mu \mathrm{L})$ or TMJ $(30 \mu \mathrm{L})$ of rats, respectively. In both models, formalin $(5 \%)$, formalin after distilled water (vehicle), formalin after boswellia extract (p.o., concentrations of 15, $30 \mathrm{mg} / \mathrm{kg})(\mathrm{n}=6)$. The number of scratching on the injected region was scored during the 9 successive periods of 5 min intervals following injection of formalin. Oral administration of boswellia $(15,30 \mathrm{mg} / \mathrm{kg})$ reduced formalin-induced SC orofacial pain behavioral responses. SC orofacial pain behavioral responses was significantly reduced at 20 35 min. In the experimental group injected into temporomandibular joints, the pain response was significantly reduced by $276.2 \pm 8.20$ and 78.3 \pm 4.7 after oral administration of boswellia $(15,30 \mathrm{mg} / \mathrm{kg})$ at $398.3 \pm 24.8$ times. As a result of the passage of time, the oral administration of boswellia showed a significant effect of reducing the temporomandibular joint pain 30 minutes after the injection of formalin. This study confirmed that oral administration of boswellia modulated the pain behavior in both models. In conclusion, boswellia extract may be a potential therapeutic treatment for orofacial pain.
\end{abstract}

Key Words: Boswellia extract, Orofacial pain, Temporomandibular joint (TMJ)

\section{서 론}

안면부 통증은 치주조직이라 일컫는 치아, 연조직, 치조 골을 포함하여 악관절에 불편감이나 통증을 느끼는 것을 의미한다. 이러한 통증은 조직 자체에 손상을 주거나 잠 재적인 손상을 줄 수 있는 유해 자극에 의해 나타나는 일 종의 경고성 감각인 통각(nociceptive pain), 손상된 조직과 그 주변조직으로부터 활성화되어 분비되는 interleukin- $1 \beta$ 등의 염증성 매개물들(Kim et al., 2014)이 유해 감수기에
작용하여 나타나는 염증성 통증(inflammatory pain), 그리고 말초와 중추 신경의 자체 손상으로 인해 유해하지 않은 자극에도 지속적으로 나타나는 신경병증성 통증(neuropathic pain)으로 구별될 수 있다(Kim and Jung, 2002; Min and Kim, 2008). 염증성 통증은 손상된 신체가 회복될 때 까지 보호 작용을 하여 잠재적인 위험 상황으로부터 벗어 날 수 있고, 차후 발생될 수 있는 상황에 대비하는 역할을 할 수 있다. 염증을 유발하는 매개체가 제거되고 분비된 매개체가 파괴되거나 흩어지면 종료되는데 이러한 염증성 통증을 제대로 치료하지 않을 경우 염증이 지속되어 말초

Received: July 26, 2018 / Revised: August 30, 2018 / Accepted: August 31, 2018

* Postgraduate researcher, ${ }^{* *}$ Professor.

${ }^{\dagger}$ Corresponding author: Min-Kyung Lee. Department of Biomedical Health Science, Dong-eui University, 176 Eongwangno(gayadong san24), Busanjin-gu, Busan 47340, Korea.

Tel: +82-51-890-4238, Fax: +82-0505-182-6878, e-mail: 1mk849@deu.ac.kr

(C) The Korean Society for Biomedical Laboratory Sciences. All rights reserved.

(C) This is an Open Access article distributed under the terms of the Creative Commons Attribution Non-Commercial License (http://creativecommons.org/licenses/by-nc/3.0/) which permits unrestricted non-commercial use, distribution, and reproduction in any medium, provided the original work is properly cited. 
신경의 손상 등으로 인하여 신경병증성 통증(neuropathic pain)으로 진행되어 만성 통증의 원인이 될 수 있기 때문 에 초기 치료가 중요하다(Min and Kim, 2008). 염증성 반응 을 조절하고 숙주에 과도한 손상을 주지 않도록 하는 활 성 항염증 기전 치료제가 개발되어 사용되고 있고, 많은 항염증제(NSAID와 코르티코 스테로이드 모두)가 개발되 었지만 안전성 프로파일 연구에서 어느 것도 분명히 안전 하지 않다는 것을 보여주고 있다(Ganapathy et al., 2011). 최 근에 합성 및 화학 약품의 부작용으로 인하여 이를 대체 할 만한 생물학적 활성 성분이 분리된 천연물의 이용으로 다양한 질병에 대한 새로운 대안 치료법으로 대두되고 있 다(Colegate and Molyneux, 1993).

보스웰리아(Boswellia Serrata)는 아라비아, 아프리카 북 동부 해안 및 인도 및 중동의 건조한 산악 지대에서 자 라는 중등도 크기 중 큰 크기 형태의 분지 나무(Leung and Foster, 1996)로 모든 열대 지방에서 넓게 퍼진 17의 속 및 600 의 종을 가지고 있으며 고대부터 민간 요법에서 천연 진통제로 불리며 염증 및 감염 질환을 치료하기 위한 다 양한 적응증으로 사용되어 왔다. 염증성 질환의 경우 체 내에 염증 매개인자인 류코트리엔(Leukotriene)이 증가하 는데, 보스웰리아는 5-lipoxygenase라는 효소 발생을 억제 하여 오메가-6 지방산에 속하는 아라키돈산(Arachidonic acid)을 류코트리엔으로 전환되는 것을 막아 염증성 질환 에 효과적이며 자가면역질환으로 인한 염증반응의 조절 에도 효과적인 것으로 알려져 있다(Ganapathy et al., 2011). 보스웰리아는 암(Shao et al., 1998), 염증(Singh and Atal, 1986), 관절염(Sharma et al., 1989), 천식(Gupta et al., 1998), 건선(Chopra et al., 1956), 대장염(Gupta et al., 2001), 고지혈 증(Pandey et al., 2005) 등과 같은 다양한 질병의 치료 목 적으로 사용되고 있다. 그러나 아직까지 보스웰리아의 염 증성 안면부위 모델에서 통증경감효과를 연구한 보고는 거의 전무한 실정이다.

따라서 본 연구는 포르말린으로 유도한 실험동물의 안 면부와 악관절 통증, 두 모델을 적용하여 보스웰리아의 통증행위반응 조절효과에 대해 확인하고자 하였다.

\section{재료 및 방법}

\section{실험동물}

실험동물은 효창사이언스(Daegu, Korea)에서 SpragueDawley계를 공급받았으며, 수컷 흰쥐(230 270 g)를 그룹 당 6 마리씩, 총 48 마리를 실험에 사용하였다. $23 \sim 24^{\circ} \mathrm{C}$ 의
일정한 환경을 유지하면서 12 시간 주/야 순환주기로 물과 사료는 자유로이 공급하였으며, 행동적인 억압 등에 의한 실험 전 스트레스를 최소화 하기 위해 유의하였다. 본 연 구는 통증연구학회의 기준에 따라 윤리적 규정에 맞게 진행하였으며, 동의대학교 동물실험윤리위원회의의 심의 를 받아 진행하였다(R2016-020).

\section{시약준비}

보스웰리아 추출물(보스웰리아 열매 추출분말; Bioprex Labs Co., Ltd., Pune Maharashtra, India)은 15, $30 \mathrm{mg} / \mathrm{kg}$ (1 $\mathrm{mL}$ )의 농도로 희석하여 경구로 투여하였다. 각 실험군은 formalin 주입군, distilled water (DW) 투여 후 5\% formalin 주입군, 보스웰리아 추출물 $(15,30 \mathrm{mg} / \mathrm{kg})$ 투여 후 $5 \%$ formalin 주입군으로 분류하였다. 보스웰리아 추출물을 주 입한 후 30 분이 경과한 뒤 formalin을 투여한 직후부터 통 증행위반응을 관찰하였다.

\section{안면부 염증성 통증 모델}

Formalin 반응 실험은 Park 등 (2011)의 연구를 참고하 여 실험 방법과 동일하게 진행하였다. 실험동물을 플라스 틱 통에 30 분 이상 적응시켜 스트레스를 최소화 시켰고, 테스트 하는 동안은 물과 사료의 섭취를 금하였다. $5 \%$ formalin을 실험동물 $(n=6)$ 의 왼쪽 수염부 피하에 주입하 여 안면부 염증성 통증을 유발하였고, 약물이 주입된 부 위를 문지르거나 긁는 행위를 통증 지표로 간주하였다. 실험 관찰 시간은 5 분 단위로 45 분간 행위반응을 관찰하 였다. Formalin으로 유도된 안면부 염증성 통증행위반응 에 보스웰리아가 미치는 영향을 확인하기 위하여 대조군 $(n=6)$ 과 실험군 $(n=6)$ 은 실험동물에 각각 $\mathrm{DW} 1 \mathrm{~mL}$ 와 보 스웰리아 $1 \mathrm{~mL}$ 를 경구 투여하고 30 분이 경과한 뒤 오른 쪽 안면부에 $5 \%$ formalin $50 \mu \mathrm{L}$ 를 주입하였다.

\section{$\mathrm{TMJ}$ 염증성 통증 모델}

통증반응을 실험하기 전에 30 분 이상 실험용 플라스틱 통에서 적응시킨 후 진행하였다. 포르말린 주입을 위하여 폴리에틸렌 튜브 한쪽 끝에 cannula를 30 gauge 주사바 늘에 연결하여 사용하였고, 이어지는 부위에는 $0.25 \times$ $8 \mathrm{~mm}$ 크기의 인슐린 주사기를 연결하였다. 우선 에테르 흡입 마취 후 오른쪽 관절강 내로 $30 \mu \mathrm{L}$ 의 포르말린을 주 입하였고, 수 초 내에 의식이 돌아오는 것을 관찰하였다. 관골궁의 후 하방 경계면과 하악 과두부위를 촉지에 의해 관절강의 위치를 유추하였고, 해당부위에 주사바늘이 관 


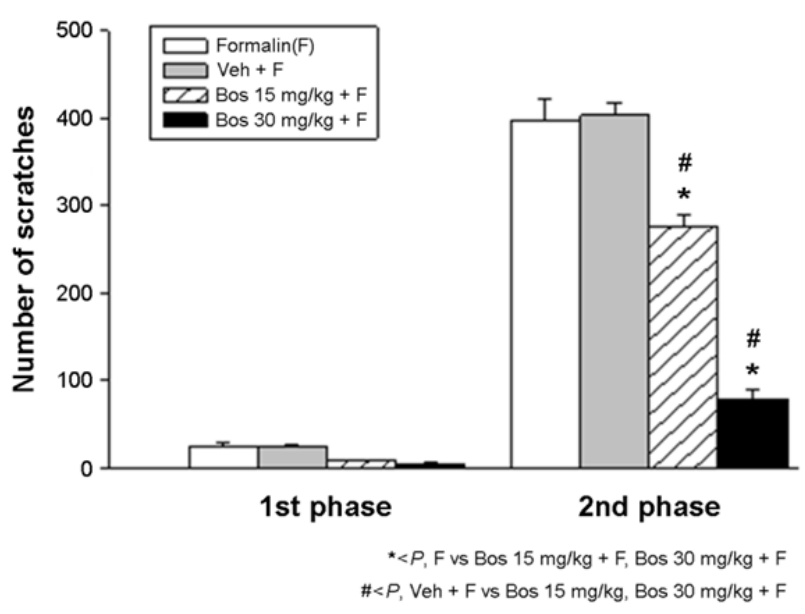

Fig. 1. The effect of the boswellia extract (Bos; $15,30 \mathrm{mg} / \mathrm{kg}$ ) on behavioral responses following injection of formalin $(5 \%, 50 \mu \mathrm{L})$ into vibrissa pad. Bos reduced behavioral responses during the second phase compared with $5 \%$ formalin group. $* P<0.05$ vs. F, $\# P<0.05$ vs. vehicle (veh) $+\mathrm{F}$.

절낭을 뜷고 하악와의 닿는 부위를 관절강 내로 인지하였 다. 본 실험 전 예비 실험을 통하여 포르말린과 동일한 양 의 $1 \%$ evans blue dye 염색제를 별도의 실험동물에 주입하 여 악관절강의 위치를 우선 확인하였다.

\section{통계분석}

실험결과는 IBM SPSS Statistic ver. 20.0 (IBM Co., Armonk, $\mathrm{NY}, \mathrm{USA}$ )을 이용하여 least significant difference 사후분 석법을 적용한 일원배치 분산분석을 하였고 유의수준은 0.05 를 기준으로 하였다, Sigmaplot 2001 (SPSS Inc., Chicago, IL, USA)을 이용하여 그래프를 나타내었다. 결과는 평균 \pm 표준오차(standard error of the mean)로 표시하였다.

\section{결 과}

\section{보스웰리아 추출물의 안면부 통증행위반응 조절효과}

염증성 안면부 통증을 유발하기 위하여 $5 \%$ formalin을 주입한 뒤 보스웰리아 추출물의 통증행위반응 조절효과 를 Fig. 1에 나타내었다. 보스웰리아 투여 시 1차 통증행 위반응은 포르말린 투여군, 대조군 $(v e h+$ 포르말린 투여 군) 그리고 약물 주입군 간의 유의한 차이가 없었으나, 2차 통증행위반응에서는 포르말린 주입군에 비해 약물 주 입군(Bos $15 \mathrm{mg} / \mathrm{kg}, 30 \mathrm{mg} / \mathrm{kg}$ ) 모두 통증행위반응이 농도 의존적으로 유의하게 감소되었다 $(P<0.05)$. 시간의 경과에

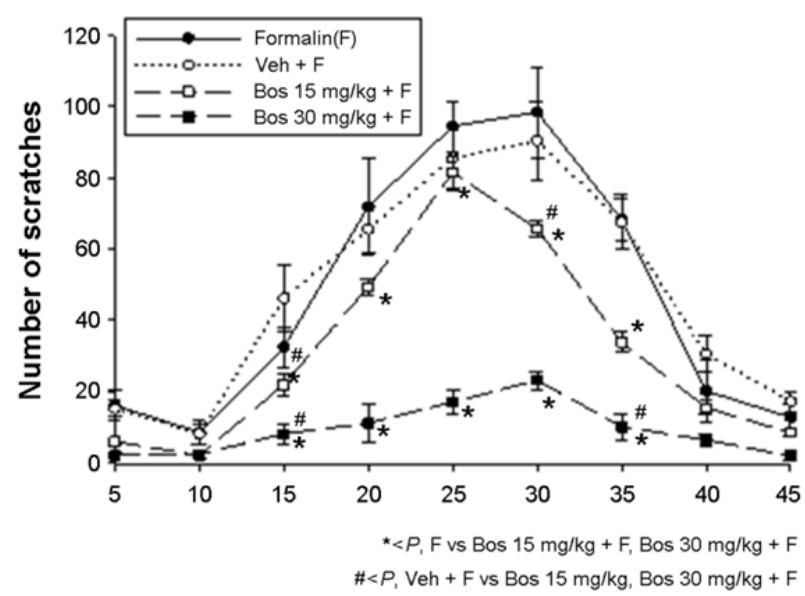

Fig. 2. Time response curve for the number of scratches responses following injection of formalin $(5 \%, 50 \mu \mathrm{L})$ into vibrissa pad 30 minutes after oral administration of boswellia extract (Bos). $* P<$ 0.05 vs. F, $\# P<0.05$, vs. vehicle (veh) $+\mathrm{F}$.

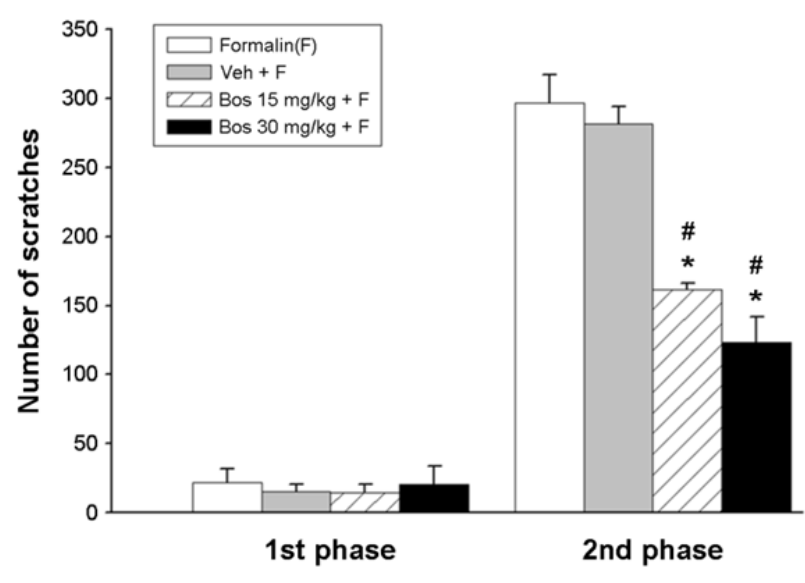

Fig. 3. The effect of the boswellia extract (Bos; $15 \mathrm{mg} / \mathrm{kg}, 30 \mathrm{mg}$ / $\mathrm{kg})$ on behavioral responses following injection of formalin $(5 \%$, $30 \mu \mathrm{L}$ ) into temporomandibular joint. Bos reduced behavioral responses during the second phase compared with $5 \%$ formalintreated group. $* P<0.05$ vs. $\mathrm{F}, \# P<0.05$ vs. vehicle (veh) $+\mathrm{F}$.

따른 통증행위반응의 변화를 Fig. 2를 통해 확인하였다. Bos $15 \mathrm{mg} / \mathrm{kg}$ 투여 시에는 약물 주입 15 35분 시점에서 효과적으로 통증행위반응이 감소되었고, Bos $30 \mathrm{mg} / \mathrm{kg}$ 투 여군에서 역시 2 차 통증행위반응에 해당하는 $15 \sim 35$ 분 경 과시점에서 통증 조절에 효과적이었다. 이러한 결과를 통 해 보스웰리아가 안면부 급성통증 조절에 효과적임을 알 수 있었다. 


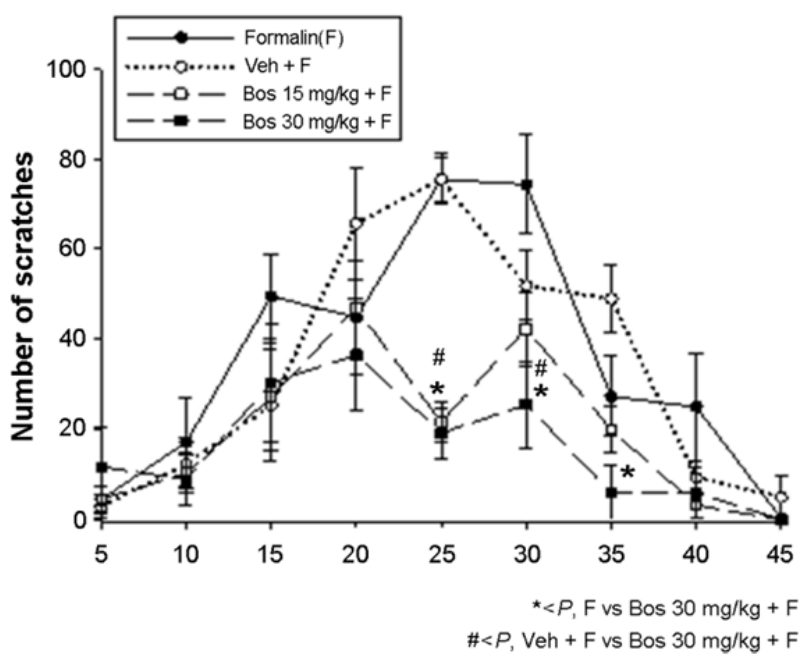

Fig. 4. Time response curve for the number of scratches responses following injection of formalin $(5 \%, 30 \mu \mathrm{L})$ into temporomandibular joint 30 minutes after oral administration of boswellia extract (Bos). $* P<0.05$ vs. F, $P<0.05$ vs. vehicle (veh) $+\mathrm{F}$.

\section{보스웰리아 추출물의 턱관절 통증행위반응 조절효과}

포르말린으로 유도한 악관절강으로 주입한 통증 모델에 서 보스웰리아 추출물의 통증조절효과는 Fig. 3에 나타내 었다. Formalin군에서 턱관절 통증행위반응은 $398.3 \pm 24.8$ 회로 나타났으며, DW군에서는 403.0 23.5 회로 DW군에 서는 턱관절 통증조절효과가 나타나지 않았다. 하지만 보 스웰리아 추출물 $(15,30 \mathrm{mg} / \mathrm{kg})$ 의 경구 투여는 각 $276.2 \pm$ $8.20,78.3 \pm 4.7$ 회로 포르말린으로 유도된 통증행위반응을 감소시켰다. Fig. 4는 행위반응의 변화를 시간의 경과에 따 른 결과 그래프로, formalin의 투여로 인한 통증행위반응 이 15 분 이후부터 증가하여 25 분에 가장 높게 나타났으며 35 분까지 지속되다가 이후 다시 감소하였다. 보스웰리아 추출물의 경구 투여는 포르말린 주입 25 30분에서 턱관 절 통증경감효과가 유의한 것을 확인할 수 있었다.

\section{고 찰}

구강 안면부의 통증 조절을 위하여 아스피린, 이부프로 펜 등의 비스테로이드성 소염진통제가 주로 처방되는데 과다 복용 시 간손상 및 장출혈 등의 부작용이 알려져 있 고, 전신질환을 가진 환자에 대한 약물처방 시 또는 복용 중인 약과의 병용에 따른 부작용으로 합성의약품의 의존 적 처방에 대한 우려로 인하여 천연약물에 대한 관심으
로 이어지고 있다(Kim et al., 2017b). 따라서 최근에는 치료 제의 원천으로 천연물을 이용한 약물의 개발이 가치 있는 전략으로 연구자들의 관심을 끌고 있다. Kim 등 (2017a)의 연구에서 포르말린으로 유도한 측두하악관절 통증 모델에 서 maca의 투여가 측두하악관절장애의 통증 발생과 조절 에 효과적임을 확인하였고, Choi 등 (2017)의 연구에서는 바오밥의 경구 투여한 결과 포르말린에 의해 유발된 안면 부 염증성 통증 실험동물에서 효과적으로 통증행위반응이 감소되는 것을 증명하였다. 또한 Lee 등 (2017)의 연구에 서 홍삼 및 흑삼 추출물이 간과 신장에 부작용을 나타내 지 않으면서 포르말린으로 유도된 안면부 통증과 Nrf2의 발현의 조절에 효과적인 것으로 나타났고, Kim 등 (2017) 의 연구에서도 안면부 피하와 턱관절 강에 각각 포르말린 을 주입하여 유발한 두 가지 통증 모델에 행위반응을 평 가한 결과, 산자나무 추출물의 경구 투여는 두 모델에서 유의한 통증경감효과를 나타내었음을 확인하였다. 따라서 안면부 통증 발생과 조절에 천연물 유래 약물들의 치료효 과를 입증하기 위하여 본 연구에서는 구강안면영역의 통 증을 실험에 적용하기 위해 안면부 피하와 턱관절 내에 formalin을 주입하여 유발한 두 통증 모델에서 천연물인 보스웰리아 추출물로 인한 통증 조절에 대한 효과를 확인 하고자 하였다.

보스웰리아는 항염증제, 진통제, 항관절염 및 항 증식제 로 인도 의약 시스템(Ayurvedic)에서 일반적으로 사용되어 지고 있는 물질이다. Gupta 등 (2001)의 연구에서는 만성 대장염의 치료에 효과적 일 수 있음을 밝혀냈고, Pandey 등 (2005)의 연구에서는 Boswellia serrata의 추출물은 혈청 $\mathrm{HDL}$ 의 증가와 함께 강한 저 콜레스테롤 혈증을 가지고 있어 활성화 된 쥐의 복강 내 대식세포에 의한 LPS로 유 도된 NO 생성을 억제하고 보호 성질을 나타나는 것을 확 인할 수 있었다. 또한 Mohamad 등 (2012)의 연구에서도 보스웰리아 추출물이 당뇨병에 영향을 미치고 신장과 간 에서 당뇨 합병증을 예방할 수 있다는 것을 밝혔다. 이처 럼 보스웰리아는 전반적으로 전신에 다양한 약리적 효능 작용이 있는 것을 확인할 수 있었다. 이를 기초로 전신에 서 심리적으로, 감각적으로 민감한 부위인 안면부 통증 완화에 보스웰리아가 미치는 영향을 확인하기 위해 실험 을 진행하였다.

본 연구의 결과를 보면 보스웰리아의 생리약리학적 특 성이 나타난 염증성 통증 모델에서 안면부 통증행위반응 이 감소한 것을 확인할 수 있었으며, 이는 포르말린으로 유도한 통증 및 염증 신호전달 경로에 영향을 미쳐 조절 
된 것으로 생각된다. 이는 통증 및 염증 신호의 조절효과 를 가지는 보스웰리아의 투여로 인하여 포르말린으로 유 도한 염증성 안면부 통증 모델에서 실험동물의 통증행위 반응을 감소시키는 것을 보아 통증경감효과가 유의한 것 을 증명하였다.

따라서 보스웰리아는 급성 염증성 안면부 통증에서 예 방 및 치료 방안에 있어 활용 가능한 천연대체약물로 사 용될 수 있을 것으로 예상된다. 하지만 전반적인 안면부 통증 모델에 적용이 가능한 지를 파악하기 위하여 만성 염증성 통증 모델에서도 영향을 미치는 지에 대한 추가 적인 연구가 필요할 것으로 사료된다.

\section{ACKNOWLEDGEMENTS}

이 논문은 2012년도 정부(미래창조과학부)의 재원으로 수행된 연구임(No. 2012M3A9B6055414).

\section{CONFLICT OF INTEREST}

No conflict of interests exists for any of the authors.

\section{REFERENCES}

Azemi ME, Namjoyan F2, Khodayar MJ, Ahmadpour F, Darvish Padok A, Panahi M. The antioxidant capacity and anti-diabetic effect of boswellia serrata triana and planch aqueous extract in fertile female diabetic rats and the possible effects on reproduction and histological changes in the liver and kidneys. Jundishapur J Nat Pharm Prod. 2012. 7: 168-175.

Choi JH, Kim YK, Kim HJ, Yoon HS, Hyun KY, Lee MK. Effects of baobab extracts on the acute orofacial pain in rat model. Journal of Korean Society of Dental Hygiene. 2017. 17: 811 $-919$.

Chopra RN, Nayar SL, Chopra IC. Glossary of Indian medicinal plants. 1956. pp. 39. Council of Industrial and Scientific Research. New Delhi, India.

Colegate SM, Molyneux RJ. Bioactive natural products: Detection, isolation and structure determination. 1993. pp. 266-267. CRC press.

Ganapathy R, Joseph JA, Krishna SG, Agarwal A. Comparative evaluation of anti-inflammatory activity of different extracts of boswellia serrata in wistar albino rats. International Journal of PharmTech Research (IJPRIF). 2011. 3: 261-267.

Gupta I, Gupta V, Parihar A, Gupta S, Lüdtke R, Safayhi H, Ammon HP. Effects of Boswellia serrata gum resin in patients with bronchial asthma: results of a double-blind, placebo controlled, 6-week clinical study. Eur J Med Res. 1998. 3: 511-514.

Gupta I, Parihar A, Malhotra P, Gupta S, Lüdtke R, Safayhi H, Ammon HP. Effects of gum resin of boswellia serrata in patients with chronic colitis. Planta Med. 2001. 67: 391-395.

Kim HJ, Kim YK, Choi JH, Lee MK. Anti-nociceptive effects of maca (Lepidium meyenii) extract on temporomandibular joint pain in rats. Journal of Korean Society of Oral Health Science. 2017a. 5: 16-21.

Kim J, Jung SJ. Pathophysiology of pain. J Korean Neurol Assoc. 2002. 20: 1-7.

Kim JH, Kim KR, Jin HJ, Im SU, Song KB, Choi YH. The effect of polycan-calcium gluconate complex on inflammatory mediators from periodontitis patients. J Dent Hyg Sci. 2014. 14: 223-229.

Kim YK, Choi JH, Yoon HS, Hyun KY, Lee MK. Analgesic effect of hippophae rhamnoides extract in orofacial pain in rats. J Dent Hyg Sci. 2017b. 17: 495-500.

Leung AY, Foster S. Encyclopedia of common natural ingredients used in food, drugs and cosmetics. 1996. pp. 389-391. New York: John Wiley and Sons. Indiana. USA.

Lee HJ, Kim YK, Choi JH, Lee JH, Kim HJ, Seong MG, Lee MK. Effects of red or black ginseng extract in a rat model of inflammatory temporomandibular joint pain. J Dent Hyg Sci. 2017. 17: 65-72.

Minn YK, Kim SM. Diagnosis and treatment of neuropathic pain. J Korean Med Assoc. 2008. 51: 1139-1148.

Pandey RS, Singh BK, Tripathi YB. Extract of gum resin of Boswellia serrata L. inhibits lipopolysaccharide induced nitric oxide production in rat macrophages along with hypolipidemic property. Indian J Exp Biol. 2005. 43: 509-516.

Park MK, Lee JH, Yang GY, Won KA, Kim MJ, Park YY, Bae YC, Ahn DK. Peripheral administration of NR2 antagonists attenuates orofacial formalin-induced nociceptive behavior in rats. Prog Neuropsychopharmacol Biol Psychiatry. 2011. 35: 982-986.

Shao Y, Ho CT, Chin CK, Badmaev V, Ma W, Huang MT. Inhibitory activity of boswellic acids from bosweliia serrataagainst human leukemia HL-60cells in culture. Planta Med. 1998. 64: 328-331.

Sharma ML, Bani S, Singh GB. Int J Immunopharmacol. 1989. 11: 647-652.

Singh GB, Atal CK. Pharmacology of an extract of Salai guggal ex-Boswellia serrata a new non steroidal anti-inflammatory agent. Agents Actions. 1986. 18: 407-412. 
https://doi.org/10.15616/BSL.2018.24.3.239

Cite this article as: Choi $\mathrm{JH}$, Hyun KY, Lee MK. Orofacial Pain Anti-Inflammatory Activity of Extracts of Boswellia Serrata in Rats. Biomedical Science Letters. 2018. 24: 239-244. 